ASTHMA

\title{
Effect of bradykinin on allergen induced increase in exhaled nitric oxide in asthma
}

\author{
F L M Ricciardolo, M C Timmers, J K Sont, G Folkerts, P J Sterk
}

Thorax 2003;58:840-845

See end of article for authors' affiliations

.....................

Correspondence to:

Dr F L M Ricciardolo,

Pulmonary Department, G

Gaslini Institute, Largo

Girolamo Gaslini 5,

16147 Genoa, Italy;

fabioricciardolo@

ospedale-gaslini.ge.it

Revised version received

24 October 2003

Accepted for publication

4 July 2003
Background: Exposure of patients with atopic asthma to allergens produces a long term increase in exhaled nitric oxide ( $\mathrm{FE}_{\mathrm{NO}}$ ), probably reflecting inducible $\mathrm{NO}$ synthase (NOS) expression. In contrast, bradykinin $(\mathrm{BK})$ rapidly reduces $\mathrm{FE}_{\mathrm{NO}}$. It is unknown whether $\mathrm{BK}$ suppresses increased $\mathrm{FE}_{\mathrm{NO}}$ production after allergen exposure in asthma, and whether it modulates $\mathrm{FE}_{\mathrm{NO}}$ via NOS inhibition.

Methods: Levels of $\mathrm{FE}_{\mathrm{NO}}$ in response to aerosolised BK were studied before (day 3) and 48 hours after (day 10) randomised diluent (diluent/placebo/BK (Dil/P/BK)), allergen (allergen/placebo/BK (All/P) BK), and allergen/L-NMMA/BK (All/L/BK)) challenges (day 8) in 10 atopic, steroid naïve, mild asthmatic patients with dual responses to inhaled house dust mite extract. To determine whether BK modulates $\mathrm{FE}_{\mathrm{NO}}$ via NOS inhibition, subjects performed pre- and post-allergen BK challenges after pretreatment with the NOS inhibitor L-NMMA in the All/L/BK period.

Results: Allergen induced a fall in $\mathrm{FE}_{\mathrm{NO}}$ during the early asthmatic reaction (EAR) expressed as $A U C_{0-1}$ (ANOVA, $p=0.04$ ), which was followed by a rise in $\mathrm{FE}_{\mathrm{NO}}$ during the late asthmatic reaction (LAR) expressed as $A U C_{1-48}$ (ANOVA, $p=0.008$ ). In the Dil/P/BK period, $\mathrm{FE}_{\mathrm{NO}}$ levels after $\mathrm{BK}$ on pre- and post-diluent days were lower than $\mathrm{FE}_{\mathrm{NO}}$ levels after placebo (difference $23.5 \mathrm{ppb}(95 \% \mathrm{Cl} 6.2$ to 40.9 ) and $22.5 \mathrm{ppb}$ (95\% $\mathrm{Cl} 7.3$ to 37.7 ), respectively; $\mathrm{p}<0.05)$. Despite the long lasting increase in $\mathrm{FE}_{\mathrm{NO}}$ following allergen challenge in the LAR, BK suppressed $\mathrm{FE}_{\mathrm{NO}}$ levels at 48 hours after allergen challenge in the All/P/BK period, lowering the increased $\mathrm{FE}_{\mathrm{NO}}$ (difference from placebo $54.3 \mathrm{ppb}(95 \% \mathrm{Cl} 23.8$ to 84.8); $p=0.003)$ to the baseline level on the pre-allergen day $(p=0.51)$. FE $E_{N O}$ levels were lower after $L^{-}$ NMMA than after placebo on pre-allergen (difference $10.85 \mathrm{ppb}(95 \% \mathrm{Cl} 1.3$ to 20.4$) ; \mathrm{p}=0.03$ ) and post-allergen (difference $36.2 \mathrm{ppb}(95 \% \mathrm{Cl} 5.5$ to 66.9$) ; p=0.03$ ) days in the All/L/BK and All/P/BK periods, respectively. L-NMMA did not significantly potentiate the pre- and post-allergen reduction in BK induced $\mathrm{FE}_{\mathrm{NO}}$.

Conclusions: Bradykinin suppresses the allergen induced increase in exhaled NO in asthma; this is not potentiated by L-NMMA. Bradykinin and L-NMMA may follow a common pathway in reducing increased NO production before and after experimental allergen exposure. Reinforcement of this endogenous protective mechanism should be considered as a therapeutic target in asthma.
$\mathrm{N}$ itric oxide $(\mathrm{NO})$ is generated from L-arginine by the enzyme NO synthase (NOS), of which constitutive (cNOS) and inducible (iNOS) isoforms have been described functionally. ${ }^{1}$ Both are present in the airways. ${ }^{2}$ cNOS (endothelial NOS (eNOS) and neuronal NOS (nNOS)) release small amounts of $\mathrm{NO}$ (in the picomolar range) within seconds in response to increases in cytosolic $\mathrm{Ca}^{2+}$. Several agonists, including bradykinin, activate cNOS upon receptor stimulation. ${ }^{3}$ In contrast, the expression of iNOS is induced by proinflammatory cytokines, a process that results in a protracted and $\mathrm{Ca}^{2+}$ independent release of high levels of NO (in the nanomolar range) ${ }^{4}$ which is inhibited by corticosteroids. ${ }^{5}$ NO formed by cNOS leads to cGMP dependent airway smooth muscle relaxation, whereas NO released by iNOS is associated with proinflammatory effects. ${ }^{78}$ Both enzyme isoforms are likely to play a role in asthma. ${ }^{78} \mathrm{NO}$ is detectable in the exhaled air of healthy volunteers ${ }^{9}$ and is increased in patients with atopic asthma. ${ }^{10}$ It has recently been shown that the increased levels of NO in the exhaled air of asthmatic patients are related to airway eosinophilic inflammation ${ }^{11}$ and to the increased expression of iNOS. ${ }^{6}$ Exhaled $\mathrm{NO}\left(\mathrm{FE}_{\mathrm{NO}}\right)$ is inhibited by treatment with inhaled corticosteroids ${ }^{5}$ and NOS inhibitors, ${ }^{12}$ suggesting that it is sensitive to steroids and produced by the enzymatic NOS pathway.

In most sensitised asthmatics, allergen exposure induces an early (EAR) and late (LAR) asthmatic response. The EAR, with early onset ( 10 minutes after exposure) and short duration ( $1-2$ hours), is followed by the LAR (3-10 hours) which is characterised by bronchoconstriction associated with airway cellular inflammation. ${ }^{13}$ Interestingly, it has been shown that the LAR is associated with increased levels of NO in the exhaled air, ${ }^{14}$ suggesting that $\mathrm{FE}_{\mathrm{NO}}$ may reflect allergic inflammation in asthmatic airways.

Bradykinin is an autacoid involved in the pathophysiology of asthma. ${ }^{15}$ Bradykinin induced hyperresponsiveness is increased by NOS inhibitors in asthma, ${ }^{16}$ suggesting that bradykinin releases $\mathrm{Ca}^{2+}$ dependent cNOS derived NO in the airways. ${ }^{16}$ Conversely, inhalation of bradykinin, ${ }^{17}$ as well as of prostaglandin $\mathrm{E}_{2}\left(\mathrm{PGE}_{2}\right),{ }^{18}$ reduces $\mathrm{FE}_{\mathrm{NO}}$ in stable asthmatics, which suggests that bradykinin has a role in modulating $\mathrm{FE}_{\mathrm{NO}}$ in the absence of disease activity. However, it is unknown whether bradykinin can regulate increased $\mathrm{FE}_{\mathrm{NO}}$ levels during late phase inflammation induced by allergen in asthma and whether it can modulate $\mathrm{FE}_{\mathrm{NO}}$ via NOS inhibition.

We measured the effect of bradykinin inhalation on NO levels in the exhaled air of asthmatic patients, both at baseline and after experimental allergen exposure in the absence or presence of the NOS inhibitor L-NMMA. This study is part of a larger project for which the study design, methods, and results for other outcome parameters have already been published. ${ }^{16}$ 


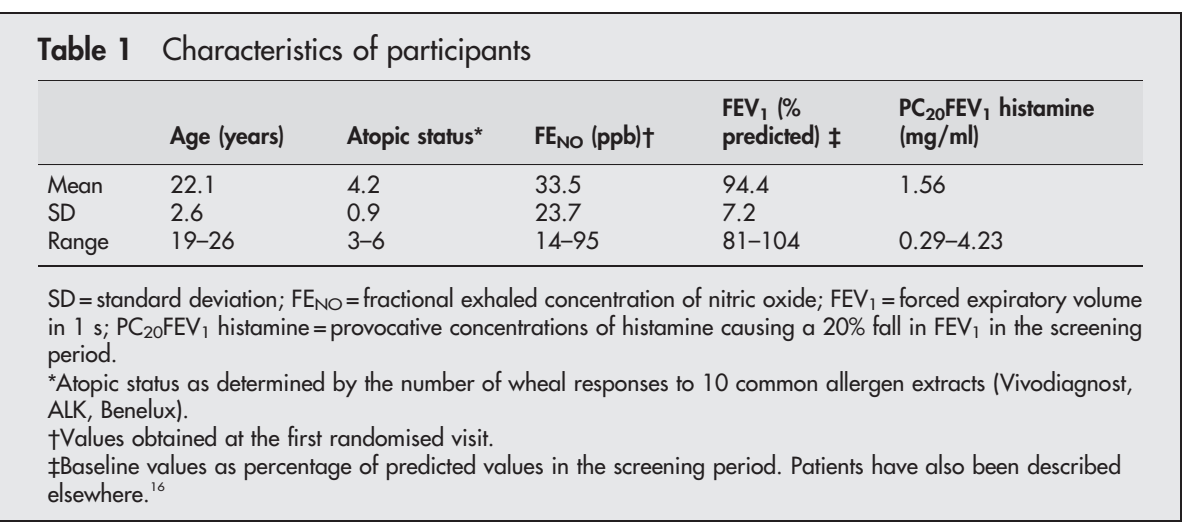

\section{METHODS \\ Subjects}

Ten non-smoking patients (five men) with mild intermittent asthma and house dust mite atopy, ${ }^{19}$ as described elsewhere, ${ }^{16}$ participated in the study (table 1). All subjects were symptom free at the time of the study and were not on regular medication. They had normal lung function and were hyperresponsive to inhaled histamine. ${ }^{20}$ Inhaled short acting $\beta_{2}$ agonists were allowed on demand until 12 hours before testing. The subjects had documented EAR and LAR to inhaled house dust mite extract in the screening period. ${ }^{20}$ The study was approved by the ethics committee of the Leiden University Medical Centre and all participants gave written informed consent.

\section{Study design}

The screening period for the selection criteria has been described previously. ${ }^{16}$ The study had a randomised, placebo controlled, crossover design and consisted of three periods (diluent/placebo/bradykinin (Dil/P/BK), allergen/placebo/ bradykinin (All/P/BK), and allergen/L-NMMA/bradykinin (All/L/BK)) of five study days each, separated by a washout interval of 2-4 weeks. During each study period the participants pretreated with placebo (Dil/P/BK and All/P/BK periods) or L-NMMA (All/L/BK period) underwent a bradykinin challenge before (day 3 ) and 48 hours after (day 10) the diluent (Dil/P/BK period) or allergen challenge (All/P/BK and All/L/BK periods, day 8; fig 1). On day 9 the participants underwent spirometric tests and $\mathrm{FE}_{\mathrm{NO}}$ monitoring (fig 1).
On day 1 of each study period a control $\mathrm{PC}_{20}$ histamine measurement was performed.

$\mathrm{FE}_{\mathrm{NO}}$ was measured (2 minutes after spirometry) at baseline, after placebo or L-NMMA, and at the end of bradykinin (after 5 minutes and every 10 minutes up to 1 hour) and allergen/diluent challenge (every 10 minutes in the first hour, every 30 minutes in the second hour, every 60 minutes up to 10 hours, and at 24 hours), when a fall in forced expiratory volume in 1 second $\left(\mathrm{FEV}_{1}\right)$ of $\geqslant 20 \%$ was achieved or after three consecutive diluent inhalations.

\section{Inhalation challenges}

Freshly prepared $\mathrm{N}^{\mathrm{G}}$-monomethyl-L-arginine (L-NMMA; Clinalfa AG, Läufelfingen, Switzerland: $10 \mathrm{mg}$ in $3 \mathrm{ml} 0.9 \%$ saline) or placebo ( $3 \mathrm{ml} 0.9 \%$ saline), bradykinin (Clinalfa AG, Läufelfingen, Switzerland: 0.0024-5.0 mg/ml), diluent, and allergen extract of Dermatophagoides pteronyssinus (SQ 503; Vivodiagnost, ALK, Benelux) were inhaled as described previously. ${ }^{16} \mathrm{FEV}_{1}$ measurements for bradykinin and allergen or diluent challenges were performed as previously reported. ${ }^{16}$

\section{Measurements of exhaled NO}

$\mathrm{FE}_{\mathrm{NO}}$ measurements were performed, according to the present recommendation, ${ }^{21}$ using a Sievers NOA 270B chemiluminescence analyser (Sievers, Boulder, CO, USA) as previously described.22 Subjects performed a slow vital capacity manoeuvre with a constant expiratory flow of $100 \mathrm{ml} / \mathrm{s}$ using online visual monitoring. An expiratory
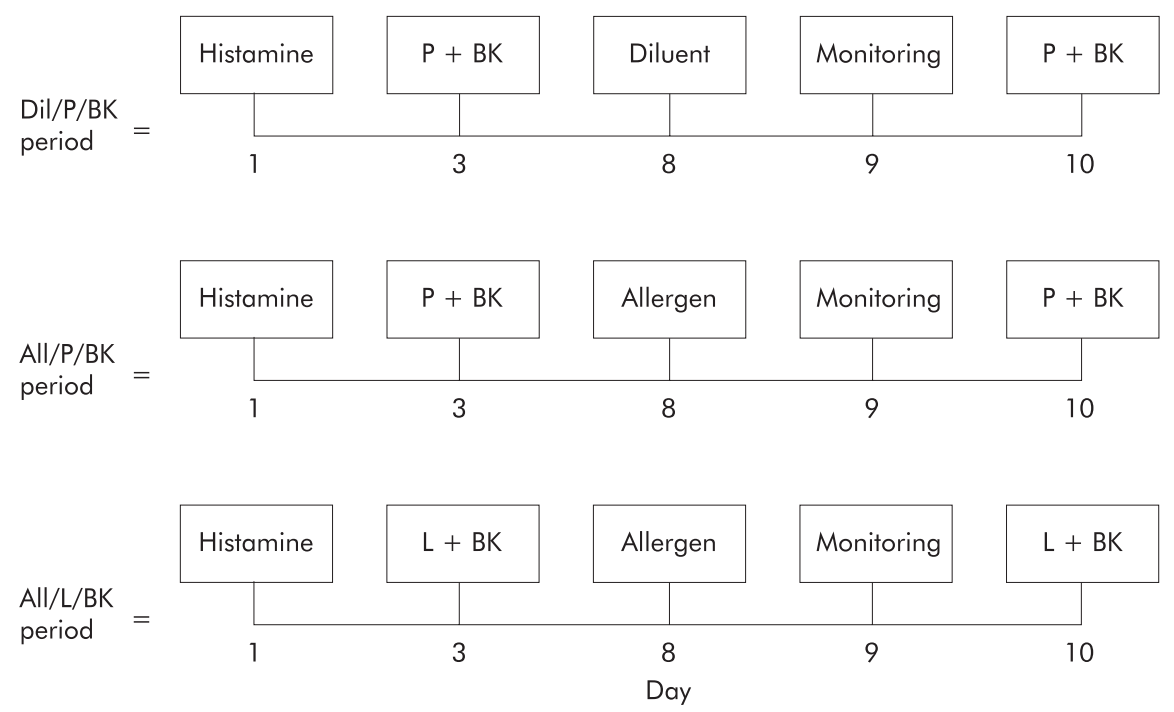

Figure 1 Study design. $\mathrm{Dil}=$ diluent; $\mathrm{All}=$ allergen; $\mathrm{P}=$ placebo; $\mathrm{BK}=$ bradykinin; $\mathrm{L}=\mathrm{N}^{\mathrm{G}}$-monomethyl-L-arginine. 
resistance of $5 \mathrm{~cm} \mathrm{H}_{2} \mathrm{O}$ was applied to prevent bias of the measurement with nasal NO. Plateau levels of NO were determined and expressed as parts per billion (ppb). Subjects inspired "NO free" air $(<1 \mathrm{ppb})$ during measurements. Three successive recordings were made at 1 minute intervals and the mean was used in the analysis.

\section{Statistical analysis}

The difference in $\mathrm{FE}_{\mathrm{NO}}$ after allergen challenge was expressed in absolute terms as the area under the time-response curve (AUC) from 0 to 48 hours (total $\mathrm{AUC}_{0-48} / 48=$ mean $\mathrm{FE}_{\mathrm{NO}}$ ), from 0 to 1 hour $\left(\mathrm{AUC}_{0-1}\right)$ in the EAR, and from 1 to 48 hours $\left(\mathrm{AUC}_{1-48}\right)$ in the LAR. The effect of bradykinin or L-NMMA on $\mathrm{FE}_{\mathrm{NO}}$ was calculated in terms of the difference between treatments or the difference from placebo with $95 \%$ confidence intervals for these differences.

Values in the text and figures are expressed as mean (SE) or $95 \%$ confidence intervals (95\% CI). In order to measure the effect of allergen and diluent on $\mathrm{FE}_{\mathrm{NO}}$ we compared $\mathrm{AUC}_{0-1}$, $\mathrm{AUC}_{1-48}$, and total $\mathrm{AUC}_{0-48} / 48$ using one way analysis of variance (ANOVA). Repeated measures ANOVA was applied to test whether there were any differences in baseline $\mathrm{FE}_{\mathrm{NO}}$ on different days and in $\mathrm{FE}_{\mathrm{NO}}$ between treatments. Two tailed paired Student's $t$ tests were applied to explore the differences. Repeated measures ANOVA of $\mathrm{PC}_{20}$ histamine and $\mathrm{FEV}_{1}$ values not described in the previous report ${ }^{16}$ were performed. In all cases a $\mathrm{p}$ value of $<0.05$ was considered significant.

Statistical analyses were performed using Statistica for Windows ( StatSoft Inc; Tulsa, OK, USA). A power calculation was based on the standard deviation (SD) of the differences between the bradykinin induced reduction in $\mathrm{FE}_{\mathrm{NO}}$ during placebo pretreatment in the Dil/P/BK (day 3) and All/P/BK (day 3 ) periods. Based on this SD ( $13.6 \%$ change in $\mathrm{FE}_{\mathrm{NO}}$ ), the current sample size allows us to detect a difference of $13.6 \%$ in $\mathrm{FE}_{\mathrm{NO}}(1 \mathrm{SD})$ between repeated bradykinin challenges (power $0.8, \alpha 0.05$ ).

\section{RESULTS}

\section{Airway responses}

$\mathrm{PC}_{20}$ histamine was similar in each study phase $(\mathrm{p}=0.28)$. Airway responses to placebo of challenge with L-NMMA ( $0.9 \%$ saline) or L-NMMA ( $10 \mathrm{mg}$ in $3 \mathrm{ml}$ ) plus diluent or allergen challenge have been reported previously. ${ }^{16}$ At 24 and 48 hours after allergen challenge $\mathrm{FEV}_{1}$ was similar to baseline in both the All/P/BK $(\mathrm{p}=0.57)$ and All/L/BK periods $(p=0.23)$. Bradykinin challenge before and after diluent or allergen provoked a similar percentage reduction in $\mathrm{FEV}_{1}$ in the Dil/P/BK period (26 (2)\% and $25(2) \%)$, All/P/BK period (27 $(2) \%$ and $28(2) \%)$, and All/L/BK period (26 (2)\% and 28 $(2) \%)$, respectively $(\mathrm{p}=0.44)$.

\section{Exhaled NO}

NO was detectable in the exhaled air of all asthmatic subjects. Baseline $\mathrm{FE}_{\mathrm{NO}}$ values in the $\mathrm{Dil} / \mathrm{P} / \mathrm{BK}$ period (day 3: 37 (11) ppb; day 8: 38 (12) ppb), All/P/BK period (day 3: 35 (9) ppb; day 8: 33 (8) ppb), and All/L/BK period (day 3: 37 (10) ppb; day 8: 31 (8) ppb) were not different (MANOVA, $\mathrm{p}=0.48)$.

There was no change in $\mathrm{FE}_{\mathrm{NO}}$ up to 48 hours after diluent challenge (day 8 ), whereas allergen challenge on day 8 reduced $\mathrm{FE}_{\mathrm{NO}}$ in the first hour after the end of the challenge in the All/P/BK and All/L/BK periods (fig 2), as shown by the significant differences between $\mathrm{AUC}_{0-1}$ for $\mathrm{FE}_{\mathrm{NO}}$ in the $\mathrm{All} / \mathrm{P} /$ BK period (19.9 ppb/h (95\% CI 9.2 to 30.7$))$, the All/L/BK period $(17.9 \mathrm{ppb} / \mathrm{h}$ (95\% CI 8.5 to 27.4$))$, and the $\mathrm{Dil} / \mathrm{P} / \mathrm{BK}$ period (38.1 ppb/h (95\% CI 9.6 to 66.6$) ; \mathrm{p}=0.04)$. $\mathrm{FE}_{\mathrm{NO}}$ was increased in the LAR after allergen challenge in the All/P/BK and All/L/BK periods (fig 2). $\mathrm{AUC}_{1-48}$ for $\mathrm{FE}_{\mathrm{NO}}$ on day 8 was

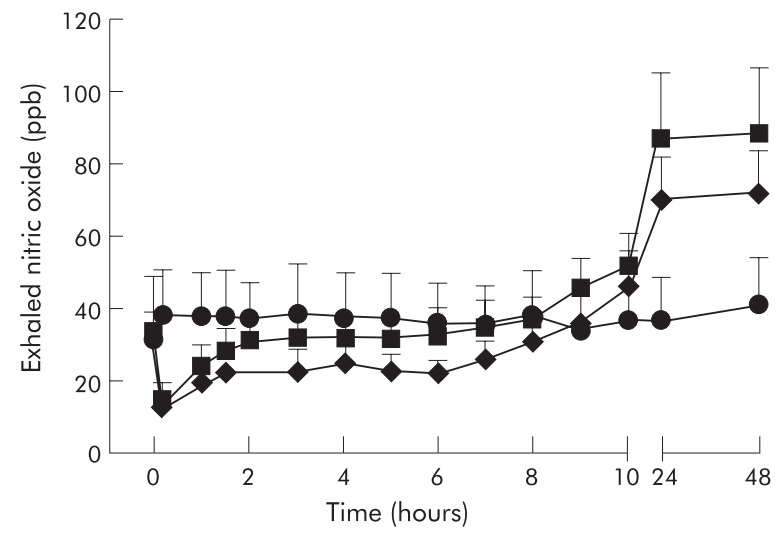

Figure 2 Time course of the change in exhaled nitric oxide levels after diluent (circles) and allergen (allergen/placebo/bradykinin: squares; allergen/L-NMMA/bradykinin: rhombus) challenges in 10 atopic patients with mild asthma. Mean (SE) values are shown.

significantly different in the All/P/BK (3282 ppb/h (95\% CI 1693 to 4870$)$ ), All/L/BK (2579 ppb/h (95\% CI 1467 to 3690)), and Dil/P/BK periods (1781 ppb/h (95\% CI 471 to 3091$)$; $\mathrm{p}=0.008$ ). The differences in total $\mathrm{AUC}_{0-48} / 48$ for $\mathrm{FE}_{\mathrm{NO}}$, interpreted as the mean $\mathrm{FE}_{\mathrm{NO}}$, on day 8 in the All/P/BK (68.8 ppb (95\% CI 35 to 102)), All/L/BK (54.1 ppb (95\% CI 31 to 77$)$ ), and Dil/P/BK periods ( $37.8 \mathrm{ppb}$ (95\% CI 10 to 65$)$ ) were significant $(p=0.009)$. The differences in all the AUCs for $\mathrm{FE}_{\mathrm{NO}}$ between diluent and the two allergen challenges are shown in table 2.

In the Dil/P/BK period $\mathrm{FE}_{\mathrm{NO}}$ values were significantly lower after bradykinin than after placebo (fig 3) on day 3 (difference $23.5 \mathrm{ppb}(95 \%$ CI 6.2 to 40.9$) ; \mathrm{p}=0.01$ ) and day 10 (difference $22.5 \mathrm{ppb}$ (95\% CI 7.3 to 37.7); $\mathrm{p}=0.008$ ). Both $\mathrm{FE}_{\mathrm{NO}}$ values after bradykinin in the Dil/P/BK period were not significantly different from the corresponding $\mathrm{FE}_{\mathrm{NO}}$ value on the pre-allergen day in the All/P/BK period $(\mathrm{p}=0.15)$. Forty eight hours after allergen challenge in the All/P/BK period bradykinin completely suppressed the increased $\mathrm{FE}_{\mathrm{NO}}$ levels (fig 3), as shown by the reduction in the allergen induced increase in $\mathrm{FE}_{\mathrm{NO}}$ (difference from placebo: $54.3 \mathrm{ppb}$ (95\% CI 23.8 to 84.8$) ; \mathrm{p}=0.003)$ to the baseline level of the preallergen day $(p=0.51)$. The difference between the reductions in $\mathrm{FE}_{\mathrm{NO}}$ induced by bradykinin from the respective placebo 48 hours after allergen in the All/P/BK period and after diluent in the Dil/P/BK period was statistically significant (31.8 ppb (95\% CI 7.1 to 56.5); $\mathrm{p}=0.017$ ).

In the Dil/P/BK and All/P/BK periods, neither placebo nor LNMMA $\left(0.9 \%\right.$ saline) changed baseline $\mathrm{FE}_{\mathrm{NO}}$ on any study days (fig 3). In the All/L/BK period the differences between the level of $\mathrm{FE}_{\mathrm{NO}}$ after L-NMMA and placebo before and after allergen were significant (All/L/BK: $10.85 \mathrm{ppb}$ (95\% CI 1.3 to 20.4), $\mathrm{p}=0.029$; All/P/BK: $36.2 \mathrm{ppb}$ (95\% CI 5.5 to 66.9 ), $\mathrm{p}=0.026)$.

After pretreatment with L-NMMA, bradykinin significantly reduced $\mathrm{FE}_{\mathrm{NO}}$ on pre-allergen (difference from L-NMMA: 14.1 ppb (95\% CI 6.8 to 21.4); $p=0.002$ ) and post-allergen (difference from L-NMMA: $29.7 \mathrm{ppb}$ (95\% CI 16 to 43.5 ); $\mathrm{p}=0.0008$ ) days (fig 3). The differences between the level of $\mathrm{FE}_{\mathrm{NO}}$ after placebo plus bradykinin in the All/P/BK period and after L-NMMA plus bradykinin in the All/L/BK period on pre- and post-allergen days ( $1.96 \mathrm{ppb}$ (95\% CI -2.1 to 6), $\mathrm{p}=0.3$; and $9.4 \mathrm{ppb}(95 \% \mathrm{CI}-0.5$ to 19.5$), \mathrm{p}=0.06$, respectively) were not statistically significant. The difference between the baseline values of $\mathrm{FE}_{\mathrm{NO}}$ ( 48 hours after allergen) on the post-allergen day (day 10) in the All/P/BK and All/L/ $\mathrm{BK}$ periods was $15.8 \mathrm{ppb}(95 \% \mathrm{CI}-5$ to 36.4$) ; \mathrm{p}=0.11)$, 


\begin{tabular}{|c|c|c|c|}
\hline & $\begin{array}{l}\text { Difference in } A U C_{0-1} \\
(\mathrm{ppb} / \mathrm{h})\end{array}$ & $\begin{array}{l}\text { Difference in } A U C_{1-48} \\
(\mathrm{ppb} / \mathrm{h})\end{array}$ & $\begin{array}{l}\text { Difference in total AUC/48 } \\
\text { (ppb) }\end{array}$ \\
\hline $\begin{array}{l}\text { Diluent (Dil/P/BK period) } v \\
\text { allergen (All/P/BK period) } \\
\text { Diluent (Dil/P/BK period) } v \\
\text { allergen (All/L/BK period) } \\
\text { Allergen (All/P/BK period) } v \\
\text { allergen (All/L/BK period) }\end{array}$ & $\begin{array}{l}18.1(-1.3 \text { to } 37.5) ; \\
p=0.06 \\
20.2(-4.8 \text { to } 45) ; \\
p=0.10 \\
2.05(-5 \text { to } 9.1) ; \\
p=0.53\end{array}$ & $\begin{array}{l}-1500(-2469 \text { to } \\
-532.7) ; p=0.006 \\
-798(-1908 \text { to } 312) ; \\
p=0.13 \\
702(-55 \text { to } 1460) ; \\
p=0.07\end{array}$ & $\begin{array}{l}-31(-51 \text { to }-11) ; \\
p=0.007 \\
-16.2(-40 \text { to } 7) ; \\
p=0.15 \\
14.7(-1 \text { to } 30) ; \\
p=0.07\end{array}$ \\
\hline
\end{tabular}

which explains the slight difference between $\mathrm{FE}_{\mathrm{NO}}$ after placebo plus bradykinin in the All/P/BK period and after LNMMA plus bradykinin in the All/L/BK period on the postallergen day.

On all bradykinin treatment days the recovery time (up to 60 minutes) was characterised by a complete spontaneous recovery in $\mathrm{FEV}_{1}$ values to baseline levels, whereas $\mathrm{FE}_{\mathrm{NO}}$ levels remained significantly lower than baseline $(\mathrm{p}<0.05$, fig 4).

\section{DISCUSSION}

This study shows, for the first time, that the allergen induced increase in $\mathrm{FE}_{\mathrm{NO}}$ in atopic asthma is suppressed by bradykinin, and that the NOS inhibitor L-NMMA significantly reduces pre- and post-allergen $\mathrm{FE}_{\mathrm{NO}}$ levels and does not potentiate the bradykinin induced reduction in $\mathrm{FE}_{\mathrm{NO}}$. Taken together, our results indicate that bradykinin, via NOS inhibition, modulates the prolonged increase in $\mathrm{FE}_{\mathrm{NO}}$ induced by allergen exposure. Our findings suggest that bradykinin inhibits excessive NO production resulting from an overexpression of the NOS pathway in asthmatic airways during an exacerbation.

The bradykinin induced fall in $\mathrm{FE}_{\mathrm{NO}}$ levels in stable asthmatics has recently been reported by Kharitonov et al. ${ }^{17}$. We have shown that bradykinin suppresses increased levels of $\mathrm{FE}_{\mathrm{NO}} 48$ hours after allergen challenge, which suggests that it has a role in modulating exacerbations of allergic inflammation. Furthermore, the finding that $\mathrm{FE}_{\mathrm{NO}}$ levels were still significantly reduced 60 minutes after the end of the pre-allergen and post-allergen bradykinin challenge, when $\mathrm{FEV}_{1}$ had completely recovered, suggests that the rapid suppression of $\mathrm{FE}_{\mathrm{NO}}$ by bradykinin has a relatively long duration and is not dependent on airway calibre. One possible explanation for the action of bradykinin is vasodilation ${ }^{15}$ with potentially enhanced NO trapping by haemoglo$\operatorname{bin}^{23}$ and/or altered diffusion of NO to the airway lumen due to mucosal swelling and gland secretion ${ }^{15}$ with subsequent airway obstruction; however, the short term effect of vasodilation and the reduction in $\mathrm{FE}_{\mathrm{NO}}$ even after recovery of the obstruction limit the validity of this hypothesis.

In this study we also examined whether bradykinin negatively modulates $\mathrm{FE}_{\mathrm{NO}}$ through inhibition of NOS. LNMMA has previously been found to reduce $\mathrm{FE}_{\mathrm{NO}}$ levels significantly in stable asthma, ${ }^{12}$ so we studied the effect of $\mathrm{L}^{-}$ NMMA on the bradykinin induced reduction in $\mathrm{FE}_{\mathrm{NO}}$. The lack of significant potentiation by L-NMMA on the bradykinin induced reduction in $\mathrm{FE}_{\mathrm{NO}}$ suggests that bradykinin and L-NMMA share a common pathway in inhibiting $\mathrm{FE}_{\mathrm{NO}}$ production in the airways of patients with asthma. It has recently been found that prostaglandins also reduce $\mathrm{FE}_{\mathrm{NO}}$ in asthmatic subjects. ${ }^{18}$ Bradykinin stimulates $\mathrm{PGE}_{2}$ release from airway epithelial cells, either by the constitutive isoform of cyclo-oxygenase enzyme (COX-1) or by the inducible isoform $(\mathrm{COX}-2),{ }^{24}$ and $\mathrm{PGE}_{2}$ negatively modulates the induction of iNOS expression at the transcriptional level. ${ }^{25}$
It is therefore possible that the reduction in $\mathrm{FE}_{\mathrm{NO}}$ induced by bradykinin is a result of the inhibition of iNOS expression through the release of $\mathrm{PGE}_{2}$. However, the rapid reduction in $\mathrm{FE}_{\mathrm{NO}}$ observed after bradykinin inhalation does not favour such a delayed mechanism, but suggests a possible direct or indirect influence of bradykinin on NOS at the posttranscriptional level. It has previously been shown that high levels of NO can downregulate NOS pathways by negative feedback, ${ }^{26}$ and also that augmented production of $\mathrm{FE}_{\mathrm{NO}}$ in the lower respiratory tract of eNOS deficient mice is associated with pulmonary iNOS overexpression, indicating a counter-regulation between the two NOS isoforms. ${ }^{27}$ Furthermore, a recent study in human mesangial cells showed a negative post-transcriptional regulation of iNOS by the NO/cGMP pathway. ${ }^{28}$ On the basis of the present results we believe that bradykinin is not only an activator of the $\mathrm{Ca}^{2+}$ dependent cNOS/CGMP pathway which modulates airway hyperresponsiveness, ${ }^{29}$ but also may downregulate excessive NO release, probably derived by iNOS, through negative feedback in allergic asthma.

In line with this hypothesis, we have previously shown that iNOS (but not eNOS or nNOS) immunostaining is higher after allergen exposure in the epithelium of bronchial biopsy sections of subjects with asthma, ${ }^{16}$ which suggests two major findings on the basis of the present data: (1) iNOS may be responsible for the increase in $\mathrm{FE}_{\mathrm{NO}}$ after allergen; (2) bradykinin should affect iNOS activity by reducing $\mathrm{FE}_{\mathrm{NO}}$ in asthmatic patients and, in particular, by suppressing the increase in $\mathrm{FE}_{\mathrm{NO}}$ after exposure to allergen.

In the present study, allergen inhalation led to two opposing changes in $\mathrm{FE}_{\mathrm{NO}}$ levels in atopic mild asthmatics. Exhaled NO tended to decrease during the EAR and exhibited a prolonged increase during and after the LAR. These findings are consistent with previous data showing the effect of allergen on $\mathrm{FE}_{\mathrm{NO}}$ levels in atopic asthmatic patients with LAR. ${ }^{14}$ In the early phase we found a reduction in $\mathrm{FE}_{\mathrm{NO}}$ levels compared with baseline, which confirms previous observations. ${ }^{30}$ In previous studies acute airways obstruction has been found to have a partial effect on $\mathrm{FE}_{\mathrm{NO}}$ levels. ${ }^{31}{ }^{32}$ It is therefore possible that bronchoconstriction could, at least partially, lead to a fall in $\mathrm{FE}_{\mathrm{NO}}$ levels during the early phase of the bronchial allergic reaction, possibly as a result of limiting NO diffusion or increased airflow velocity in constricted airways. We also postulate an indirect effect of allergen on $\mathrm{FE}_{\mathrm{NO}}$ levels during the early phase reaction via the release of proinflammatory mediators such as kinins or prostaglandins. ${ }^{17} 18$

Exhaled NO appeared to increase 9-48 hours after allergen inhalation, confirming a previous report. ${ }^{14}$ In the latter study the authors observed a decline in $\mathrm{FE}_{\mathrm{NO}}$ by 27 hours. The longer duration of increased $\mathrm{FE}_{\mathrm{NO}}$ in our study could be a reflection of a possibly higher level of allergic inflammation induced by allergen exposure. Several lines of evidence suggest that $\mathrm{FE}_{\mathrm{NO}}$ reflects iNOS expression in asthma, ${ }^{56}$ which recognises that $\mathrm{FE}_{\mathrm{NO}}$ is a non-invasive marker of 

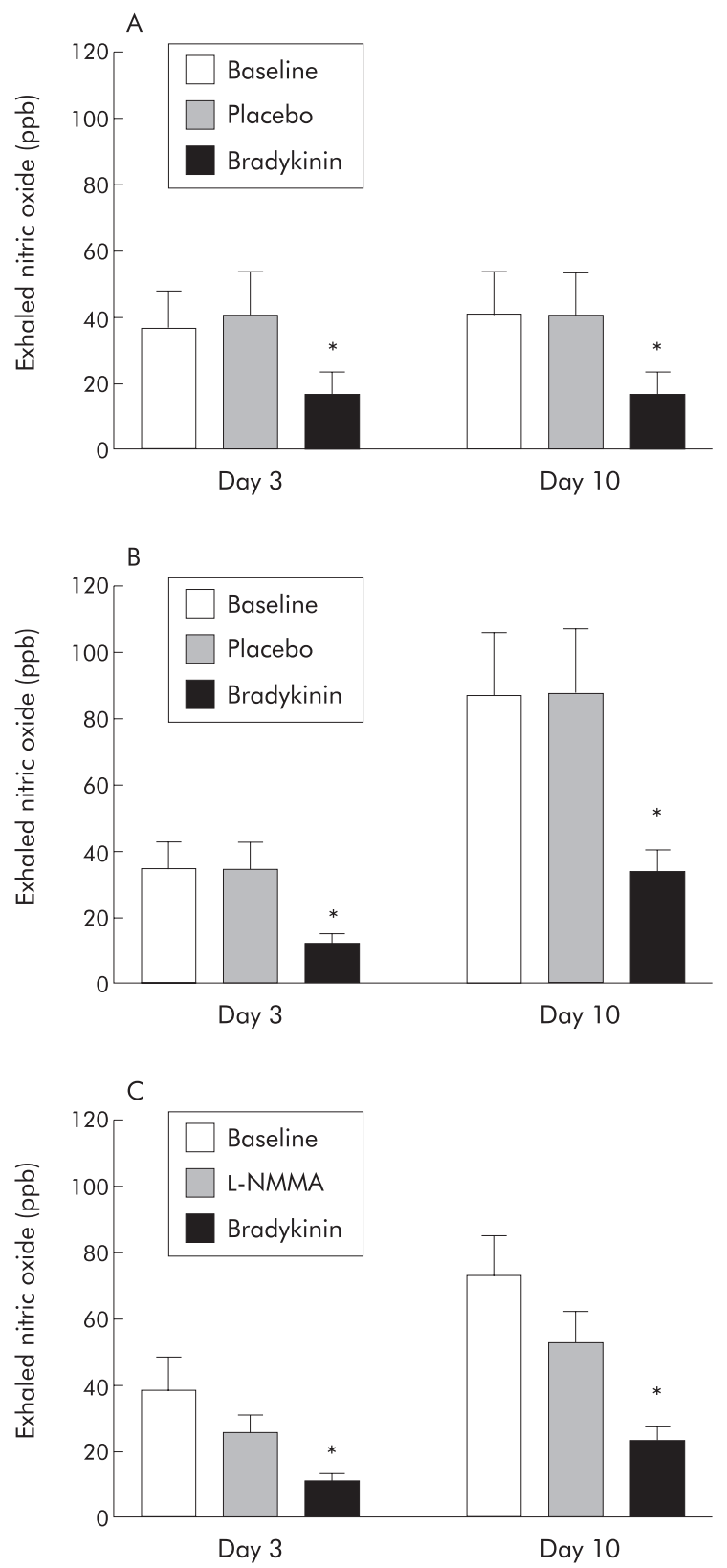

Figure 3 Effect of bradykinin challenge on exhaled nitric oxide in (A) the diluent/placebo/bradykinin period, (B) the allergen/placebo/ bradykinin period, and (C) the allergen/L-NMMA/bradykinin period. Exhaled nitric oxide levels were measured before pre-treatment (open columns), after pretreatment (with placebo or L-NMMA: shaded columns), and 5 minutes after bradykinin challenge (filled columns) on days 3 and 10 of each study period. On day 8 diluent (diluent/placebo/ bradykinin) and allergen (allergen/placebo/bradykinin and allergen/LNMMA/bradykinin) challenges were performed. Mean (SE) values are shown. * $p<0.05 v$ respective placebo or L-NMMA.

airway inflammation in asthma. ${ }^{33}$ The delayed and long term increase in $\mathrm{FE}_{\mathrm{NO}}$ during the LAR could be explained by the action of proinflammatory cytokines released from inflammatory cells recruited to the airways after allergen exposure, and of reactive oxygen species with subsequent upregulation of iNOS expression. ${ }^{34}{ }^{35}$ Furthermore, an additional explanation could be derived from the recent evidence that airway acidification converts nitrite $\left(\mathrm{NO}_{2}{ }^{-}\right)$to $\mathrm{NO}$ gas in quantities consistent with those observed in expired air during an asthma exacerbation, ${ }^{36}$ or after the LAR to allergen.
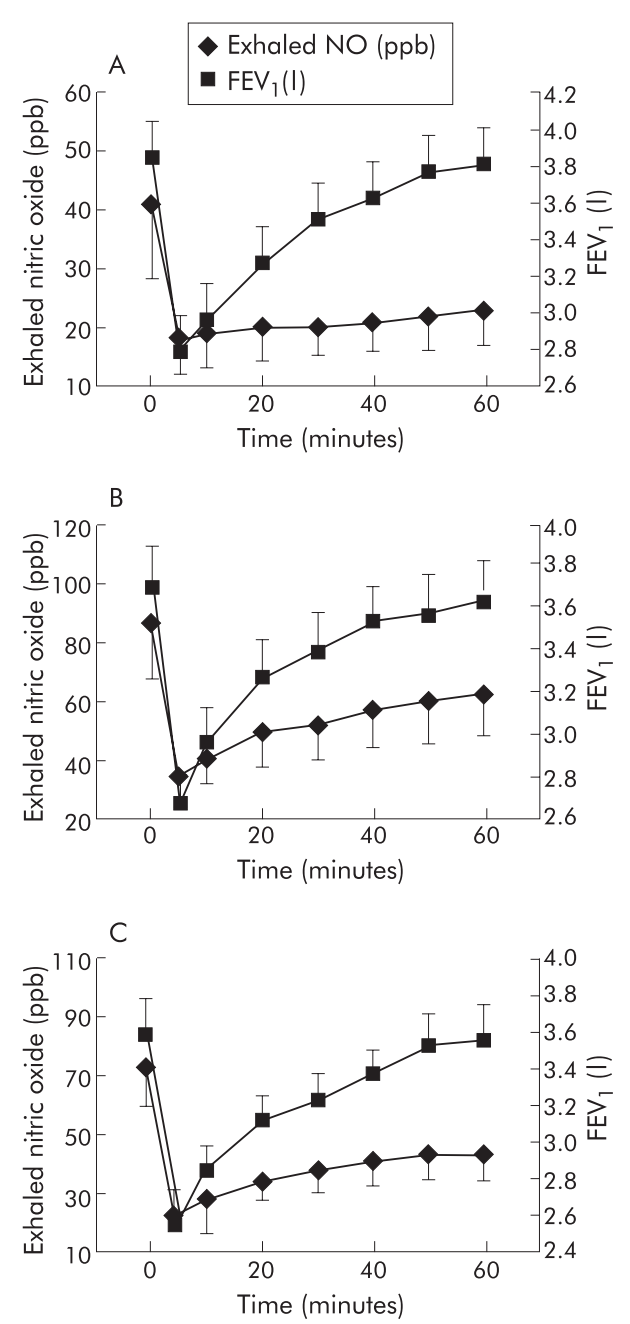

Figure 4 Time course of the change in exhaled nitric oxide (rhombus) and forced expiratory volume in one second ( $\mathrm{FEV}_{1}$; squares) during the recovery period after diluent in $(A)$ the diluent/placebo/bradykinin period and after allergen in (B) the allergen/placebo/bradykinin period and (C) the allergen/L-NMMA/bradykinin period on the day of bradykinin challenge (day 10) in 10 atopic patients with mild asthma. Mean (SE) values are shown.

To avoid differences in $\mathrm{FE}_{\mathrm{NO}}$ as a result of smoking or medication use, we selected a homogeneous group of nonsmoking, atopic, mild intermittent asthmatic subjects who were not using any steroid medication before or during the experiments. It has recently been shown that repeated forced vital capacity (FVC) manoeuvres significantly reduce $\mathrm{FE}_{\mathrm{NO}}$ levels in healthy and asthmatic subjects by $13 \%$ and $10 \%$, respectively. ${ }^{37}$ Even though our $\mathrm{FE}_{\mathrm{NO}}$ measurements were performed 2 minutes after an FVC manoeuvre, we do not consider that it had any effect because no effect on the $\mathrm{FE}_{\mathrm{NO}}$ measurement was seen following diluent.

NO released by iNOS is likely to exert proinflammatory activities such as induction of eosinophil chemotaxis and activation of the Th2 driven immune response, ${ }^{811}$ as observed during the late phase response to inhaled allergen. The bradykinin induced suppression of raised $\mathrm{FE}_{\mathrm{NO}}$ levels during the late phase suggests that bradykinin can modulate allergic inflammation exacerbations in the airways by the inhibition of proinflammatory NOS. On the basis of our study, a clinically relevant scenario could be outlined in patients with asthma where an acute inflammatory mediator (bradykinin) could have a modulatory role in limiting the effect of a detrimental long lasting inflammatory pathway (iNOS). The 
reinforcement of such endogenous protective mechanisms should be considered as a potential therapeutic target in asthma.

\section{ACKNOWLEDGEMENTS}

This study was supported by a Research Fellowship of the European Respiratory Society (ERS).

\section{Authors' affiliations}

F L M Ricciardolo, M C Timmers, P J Sterk, Department of Pulmonology, Leiden University Medical Center, The Netherlands

F L M Ricciardolo, Pulmonary Department, G Gaslini Institute, Genoa, Italy

J K Sont, Department of Medical Decision Making, Leiden University Medical Center, The Netherlands

G Folkerts, Department of Pharmacology and Pathophysiology, Faculty of Pharmacy, Utrecht University, The Netherlands

\section{REFERENCES}

1 Moncada S, Palmer RMJ, Higgs EA. Nitric oxide: physiology, pathophysiology, and pharmacology. Pharmacol Rev 1996;43:109-42.

2 Gaston B, Lobzik L, Stamler JS. Distribution of nitric oxide synthase in the lung. In: Zapol WM, Bloch KD, eds. Nitric oxide and the lung. New York: Marcel Dekker, 1997:75-86.

3 Nathan C. Nitric oxide as a secretory product of mammalian cells. FASEB J 1992;6:3051-64.

4 Morris SM, Billiar TR. New insights into the regulation of inducible nitric oxide synthesis. Am J Physiol 1994;266:E829-39.

5 Kharitonov SA, Yates DH, Barnes PJ. Inhaled glucocorticoids decrease nitric oxide in exhaled air of asthmatic patients. Am J Respir Crit Care Med 1996;153:454-7

6 Saleh D, Ernst P, Lim S, et al. Increased formation of the potent oxidant peroxynitrite in the airways of asthmatic patients is associated with induction of nitric oxide synthase: effect of inhaled glucocorticoid. FASEB J

1998; 12:929-37.

7 Nijkamp FP, Folkerts G. Nitric oxide and bronchial reactivity. Clin Exp Allergy 1994;24:905-14.

8 Barnes PJ, Liew FY. Nitric oxide and asthmatic inflammation. Immunol Today 1995; 16:128-30.

9 Gustafsson LE, Leone AM, Persson MG, et al. Endogenous nitric oxide is present in exhaled air of rabbits, guinea pigs and humans. Biochem Biophys Res Commun 1991;181:852-7.

10 Gratziou Ch, Lignos M, Dassiou M, et al. Influence of atopy on exhaled nitric oxide in patients with stable asthma and rhinitis. Eur Respir $J$ 1999; 14:897-901.

11 Jatakanon A, Lim S, Kharitonov SA, et al. Correlation between exhaled nitric oxide, sputum eosinophils, and methacholine responsiveness in patients with mild asthma. Thorax 1998:53:91-5.

12 Yates DH, Kharitonov SA, Robbins RA, et al. Effect of a nitric oxide synthase inhibitor and a glucocorticosteroid on exhaled nitric oxide. Am J Respir Crit Care Med 1995; 152:892-6.

13 Weersink EJM, Postma DS, Aalbers R, et al. Early and late asthmatic reaction after allergen challenge. Respir Med 1994;88:103-14.

14 Kharitonov SA, O'Connor BJ, Evans DJ, et al. Allergen-induced late asthmatic reactions are associated with elevation of exhaled nitric oxide. Am J Respir Crit Care Med 1995;151:1894-9.

15 Barnes PJ. Bradykinin. In: Barnes PJ, Grunstein MM, Leff AR, Woolcock AJ, eds. Asthma. New York: Lippincott-Raven, 1997:577-84.
16 Ricciardolo FLM, Timmers MC, Geppetti P, et al. Allergen-induced impairment of bronchoprotective nitric oxide synthesis in asthma. J Allergy Clin Immunol 2001; 108:198-204.

17 Kharitonov SA, Sapienza MM, Chung KF, et al. Prostaglandins mediate bradykinin-induced reduction of exhaled nitric oxide in asthma. Eur Respir J 1999; 14:1023-7.

18 Kharitonov SA, Sapienza MA, Barnes PJ, et al. Prostaglandins $E_{2}$ and $F_{2 \alpha}$ reduce exhaled nitric oxide in normal and asthmatic subjects irrespective of airway caliber changes. Am J Respir Crit Care Med 1998;158:1374-8.

19 National Heart, Lung and Blood Institute. Expert panel record 2. Guidelines for the diagnosis and management of asthma, NIH Publication No 97-4051. Bethesda, MD: National Institutes of Health, 1997.

20 Sterk PJ, Fabbri LM, Quanjer PhH, et al. Airway responsiveness: standardized challenge testing with pharmacological, physical and sensitizing stimuli in adults. Eur Respir J 1993;6(Suppl 16):53-83.

21 American Thoracic Society. Recommendations for standardized procedures for the online and offline measurement of exhaled lower respiratory nitric oxide and nasal nitric oxide in adults and children. Am J Respir Crit Care Med 1999; 160:2104-17.

22 De Gouw HWFM, Marshall-Partridge SJ, van der Veen H, et al. Role of nitric oxide in the airway response to exercise in healthy and asthmatic subjects. J Appl Physiol 2001;90:586-92.

23 Gow AJ, Stamler JS. Reactions between nitric oxide and haemoglobin under physiological conditions. Nature 1998;391:169-73.

24 Saunders MA, Belvisi MG, Cirino $G$, et al. Mechanisms of prostaglandin $E_{2}$ release by intact cells expressing cyclooxygenase-2: evidence for a "twocomponent" model. J Pharmacol Exp Ther 1999;288:1101-6.

25 Tetsuka T, Daphna-lken D, Srivastava SK, et al. Cross-talk between cyclooxygenase and nitric oxide pathways: prostaglandin $\mathrm{E}_{2}$ negatively modulates induction of nitric oxide synthase by interleukin 1. Proc Natl Acad Sci USA 1994;91:12168-72.

26 Griscavage JM, Hobbs AJ, Ignarro $\amalg$. Negative modulation of nitric oxide synthase by nitric oxide and nitroso compounds. Adv Pharmacol 1995;34:215-34.

27 Cook SP, Vollenweider P, Menard B, et al. Increased eNO and pulmonary iNOS expression in eNOS null mice. Eur Respir J 2003;21:770-3.

28 Perez-Sala D, Cernuda-Morollon E, Diaz-Cazorla M, et al. Posttranscriptional regulation of human iNOS by the NO/cGMP pathway. Am J Physiol $2001 ; 280$ :F466-73.

29 Figini M, Ricciardolo FLM, Javdan P, et al. Evidence that epithelium-derived relaxing factor released by bradykinin in the guinea pig trachea is nitric oxide. Am J Respir Crit Care Med 1996;153:918-23.

30 Dweik RA, Comhair SAA, Gaston B, et al. NO chemical events in the human airway during the immediate and late antigen-induced asthmatic response. Proc Natl Acad Sci USA 2001;98:2622-7.

31 De Gouw HWFM, Hendriks J, Woltman AM, et al. Exhaled nitric oxide (NO) is reduced shortly after bronchoconstriction to direct and indirect stimuli in asthma. Am J Respir Crit Care Med 1998;158:315-9.

32 Ho LP, Wood FT, Robso A, et al. The current single exhalation method of measuring exhaled nitric oxide is affected by airway calibre. Eur Respir J 2000;15:1009-13.

33 Gustafsson LE. Exhaled nitric oxide as a marker in asthma. Eur Respir J 1998;11(Suppl 26):49S-52S.

34 Hamid Q, Springall DR, Riveros-Moreno V, et al. Induction of nitric oxide synthase in asthma. Lancet 1993;342:1510-3.

35 Adcock IM, Brown CR, Kwon OJ, et al. Oxidative stress induces NF-kB DNA binding and inducible NOS mRNA in human epithelial cells. Biochem Biophys Res Commun 1994:199:1518-24.

36 Hunt JF, Fang K, Malik R, et al. Endogenous airway acidification. Implications for asthma pathophysiology. Am J Respir Crit Care Med 2000;161:694-9.

37 Silkoff PE, Wakita S, Chatkin J, et al. Exhaled nitric oxide after $\beta_{2}$-agonist inhalation and spirometry in asthma. Am J Respir Crit Care Med 1999; 159:940-4. 